\title{
Evidence of low affinity immunoglobulin epsilon Fc receptor gene in an invertebrate: The sea star Asterias rubens
}

\author{
Michel Leclerc ${ }^{* *}$ and Nicolas Kresdorn ${ }^{2}$ \\ 1556 rue Isabelle Romée, Sandillon, France \\ ${ }^{2}$ GenXPro, Frankfurt, Germany
}

\begin{abstract}
Kappa genes and complement genes were found in the sea star in the past. Recently, we discovered a "sea star IgKappa gene". We present now a low affinity Ig epsilon Fc receptor gene when compared to mouse genome, in immunized and non-immunized sea stars to HRP.
\end{abstract}

\section{Introduction}

In 2011, it was striking to discover Kappa genes [1] in the transcriptome of Asterias rubens, when compared to mouse genome. Two years later we found complement genes [2] from C1 to C9. At last, we cloned a gene, with a SMART kit PCR cDNA synthesis (Clontech) [3]: the "sea star Igkappa gene" with two Ig sites, which lead to the synthesis of a primitive antibody: an anti-HRP antibody, by the use of a E.coli plasmid [4]. To date we find all these elements in immunized and non-immunized sea stars to HRP (Horse- radish Peroxydase) and the emergence of low affinity Immunoglobulin epsilon Fc receptor, we describe now.

\section{Material and methods}

Sea stars were obtained from the Biology Institute (Gothenburgh University). Immunizations, genomic studies were already described [1]. After ligation of adapters for Illumina's GSII sequencing system, the cDNA was sequenced on the Illumina GSII platform sequencing. 1.100 $\mathrm{bp}$ from one side of the approximatey $200 \mathrm{bp}$ fragments sequences were assembled using Velvet [5].

\section{Results}

Low affinity Immunoglobulin epsilon $\mathrm{Fc}$ receptor appear in immunized and non-mmunized sea star genomes.Result with nonmmunized animals is given:

One contig (Contig10847) could be annotated via BLASTX to Mus musculus "Isoform 3 of Low affinity immunoglobulin epsilon Fc receptor" from the Swissprot database (FCER2_MOUSE), with an e-value of $1.49 \mathrm{e}-11$. On an aligned region of 118 amino acids, 63 positive and 40 identical amino acids were found.

5'TCCATTAGGGCAATGAGTGGGACTGCGCGGCTTGGCACAGATCATCCCTTTTCTATCACGACACCTCGAGTCTTTCCACTTGCCGTTGCTAATCTGTAATGCCACACAGTTATTCTCCAATGATTCGACTCCAGACAGCTCAGTTTGCTCTTCTTCGATGAAGTTCGTGTAGTTGACGGGGGAATCGTTTGACCATTTC-
CAATCGCTTTCGTTGTGTGTATCATGGAGCCCGATCCACACGTCCCTGTCAATTAGGTCGGTAAGAAAATCATTAATTTCTTGGTCAGTGATGGCGACCAGCCTAGCGCCGTCGTATTTAGTGCACTTCTGTTCAGCATCGACCCAGCGTGCTACATCGTCTGGAATCCAGAAGCATTCATCACGGAAGAGATGGCCGTTGTTTAGGCAGTACTGTGGTTGACCACGTACTGTTTGAAGAAGATGAGCTGACCCAATAACCATCATCATCACGAATGGAATCATTGTGAATTTGTTTGAGATACGTCCGATACGTCCGTCCGTAGATGAAAAAACTGCCGAAGTCTCTCACATAATTCCACCAGGCATTGTTGATGCCTTGCTGCTCTATGGTTGATGCTTGGTGGCAGTCCACGAAAGAATGTGCAGTTAGGGAAAGTCCAGCTTGTATATCTC3"

\section{Discussion and conclusion}

A similar result was obtained with immunized sea stars. The existence of immunoglobulin $\mathrm{Fc}$ receptor gene corroborates the presence of an immunoglobulin in sea star immune system.

In mouse, it is well-known that Fc receptor binds the antibody to the antigen. In this interaction, antibody can regulate the immune response [6] through Fc receptor. In mouse the antibody is an IgE. We have not found IgE gene in sea star genome but exclusively Kappa genes. We suggest again that the sea star primitive antibody is composed of 4 light kappa chains [7] without disulfid bonds.

\section{References}

1. Leclerc M, Dupont S, Ortega-Martinez O, Hernroth B, Krezdorn N, et al. (2011) Evidence of Kappa genes in the sea-star Asterias rubens (Echinoderma). Immunol Lett 138: 197-198. [Crossref]

Correspondence to: Michel Leclerc, 556 rue Isabelle Romée, 45640 Sandillon, France, Tel: 02384102 09; E-mail: mleclerc45@gmail.com

Key words: invertebrate, sea star, $f c$ receptor, immunoglobulin, primitive antibody

Received: April 02, 2016; Accepted: April 22, 2016; Published: April 25, 2016 
2. Leclerc M and Otten P (2013) Revealed Oncologic Markers In The Sea Star Antibody Response To H.R.P. Immunol Lett 151: 68-70.

3. Vincent N, Osteras M, Otten P, Leclerc M (2014) A new gene in A. rubens: A sea star Ig kappa gene. Meta gene 2: 320-322. [Crossref]

4. Leclerc M and Kresdorn N (2014) Asterias Rubens: The Toll-Like Receptors (Tlrs). Saj Biotechnology 1:104
5. Zerbino DR (2007) Asterias Rubens: Evidence Of Immune Genes.Gen Res 18: 821829

6. Nimmerjahn F and Ravetch JV (2008) Fc $\gamma$ receptors as regulators of immune responses. Nature Reviews Immunology 8: 34-47

7. Leclerc M (2000) Evidence of Kappa genes in the sea-star Asterias rubens (Echinoderma). Eur J Morph 38: 206-207.

Copyright: $\left({ }^{2} 2016\right.$ Leclerc M. This is an open-access article distributed under the terms of the Creative Commons Attribution License, which permits unrestricted use, distribution, and reproduction in any medium, provided the original author and source are credited. 